\title{
INOVAR E EMPREENDER NA ESCOLA DE ENGENHARIA DA UNIVERSIDADE FEDERAL DO RIO GRANDE DO SUL: DESAFIO DOS CALOUROS 2020/1
}

\author{
BeatrizFerreira Webber*-webberbeatriz@outlook.com \\ Diego Menezes Gonçalves* - diegomenezes486@gmail.com \\ João Víctor Machado de Costa*_joao.victor.mdcosta@gmail.com \\ José Henrique de Souza Silva* - hiquess@ hotmail.com \\ Marcelo Zen Preto* - celopreto@gmail.com \\ Simone Ramires*_simone.ramires@ufrgs.br \\ Thaís Santos Landfeldt* - thais.s.land@gmail.com \\ Universidade Federal do Rio Grande do Sul* \\ Avenida Osvaldo Aranha, $n^{\circ} 99$ \\ 90035-190 - Porto Alegre - RS
}

\begin{abstract}
Resumo: O desafio de formar engenheiros empreendedores e inovadores na Escola de Engenharia (EE) da Universidade Federal do Rio Grande do Sul (UFRGS) surge desde o momento em que os calouros dos 13 cursos de Engenharia são inseridos na Universidade e sendo desafiados a propor projetos de melhorias, que tenham viés sustentável, abrangendo as esferas econômica, social e ambiental e ainda alinhar com os 17 Objetivos do Desenvolvimento Sustentável da ONU. Ainda, são apresentados aos diversos ambientes acadêmicos da Universidade, como Empresas Juniores, Secretaria de Desenvolvimento Tecnológico (SEDETEC), Fundação Centenário, Laboratórios e a partir disso usufruir da infraestrutura da Universidade para criar, inovar, empreender e desenvolver projetos, interagir com outras áreas de conhecimento, buscar alternativas para os problemas apresentados, visando intervenção, melhoria contínua e, propor soluções de sustentabilidade, onde o objeto é a utilização de recursos já existentes ou aprimorá-los. Sendo assim, surge o projeto Reliqua Biogás proposto por calouros no projeto Acolhimento dos Calouros da EE Desafio "Como tornar a UFRGS mais sustentável”. O projeto em questão estuda a viabilidade da implementação de um biodigestor para geração de biogás no Hospital de Clínicas de Porto Alegre (HCPA), justificando-se pelo grande volume de resíduos sólidos orgânicos gerados pela Instituição e a necessidade de inovação na gestão desses resíduos assim como diminuir custos com a destinação deles.
\end{abstract}

Palavras-chave: Engenharia. Sustentabilidade. Biogás. Inovação. Desafio.

\section{INTRODUÇÃO}

A percepção da falta de engenheiros qualificados no país aumenta quando a Indústria requer profissionais que ultrapassem os limites do pensamento objetivo e quantitativo tradicional. Infere-se que é necessário a melhoria nas competências interpessoais, na educação 
primária e no estímulo da formação técnica e científica, além de demandar mais das habilidades cognitivas do engenheiro, as que se referem a inovação, como a criatividade, criticidade, indução, empreendedorismo, análise de riscos e ser capaz de resolver problemas. (CONFEDERAÇÃO NACIONAL DA INDÚSTRIA, 2015).

A partir disso, percebe-se a importância do incentivo à inovação e ao empreendedorismo por parte das Faculdades e Universidades nacionais, para que a demanda por esses profissionais seja cumprida. Um dos desafios que a sociedade encontra na contemporaneidade é o de promover um futuro que seja social, econômica e ambientalmente sustentável para futuras gerações, de forma tal que garanta o bem-estar da posterior e da atual geração, sem que nenhuma seja prejudicada ou desfavorecida. Para isto, é necessário que seja repensado a perspectiva de mundo atual e se priorize os vieses que percebem a correlação entre fenômenos sociais, ambientais e econômicos. (LOUREIRO; PEREIRA; JÚNIOR, 2016).

Nesse sentido, segundo Cordeiro et al (2008) a área de engenharia, é referência quando se diz respeito a inovação na indústria e outros setores econômicos, assim, infere-se, que a educação em engenharia se torna um elemento essencial para o êxito da integração educaçãoempresa, cujo vínculo contribui diretamente para o favorecimento das necessidades da sociedade. A partir disso, a Universidade Federal do Rio Grande do Sul compreendeu seu papel como peça chave e teve a percepção de que o desafio de formar engenheiros empreendedores e inovadores surge desde o momento em que os calouros são inseridos na Universidade. Para isso, implementou o projeto "DESAFIO DOS CALOUROS 2020/1 Como tornar a UFRGS mais sustentável", para que os calouros sejam desafiados a propor projetos de melhorias, que tenham viés sustentável, abrangendo as esferas econômica, social e ambiental e ainda alinhar com os 17 Objetivos do Desenvolvimento Sustentável da ONU. Ainda, são apresentados aos diversos ambientes acadêmicos da Universidade, como Empresas Juniores, Secretaria de Desenvolvimento Tecnológico (SEDETEC), Fundação Centenário, Laboratórios e a partir disso usufruir da infraestrutura da Universidade para criar, inovar e empreender e desenvolver projetos, interagir com outras áreas de conhecimento, buscar alternativas para os problemas apresentados, visando intervenção, melhoria contínua e, propor soluções de sustentabilidade, onde o objeto é a utilização de recursos já existentes ou aprimorá-los.

Como resultado dessa proposta foi possível observar o surgimento de vários projetos relacionados a sustentabilidade, entre eles o Reliqua Biogás que estuda a viabilidade da implementação de um biodigestor para geração de biogás no Hospital de Clínicas de Porto Alegre. A proposta em questão está em fase de ideação e justifica-se pela necessidade de redução de custos quanto a geração de resíduos sólidos orgânicos do Hospital de Clínicas de Porto Alegre (HCPA), pelos benefícios da geração de biogás para energia térmica e Gás Natural Veicular (GNV), bem como seus coprodutos para biofertilização.

Nesse sentido, o presente estudo tem o objetivo de apresentar e discutir conceitos como o engajamento do curso de engenharia com a sociedade, a necessidade e a importância do acolhimento de calouros, a identificação de lacunas como habilidades e competências de um engenheiro, inovação e empreendedorismo, sustentabilidade e responsabilidade social, assim como apresentar a proposta de projeto Reliqua Biogás destacando a inovação e o empreendedorismo referentes a ela. 


\section{NECESSIDADE E IMPORTÂNCIA DO ACOLHIMENTO DE CALOUROS}

Frequentemente ocorre de estudantes recém chegados à universidade (calouros), sentemse deslocados, visto que muitas vezes vêm de outras cidades, estados ou até mesmo de diferentes países, quando entram na universidade não possuem amigos próximos ou sofrem com a dificuldade de integração. Entretanto, atualmente muitas Universidades, como por exemplo a Universidade Federal do Rio Grande do Sul (UFRGS), aderiram a criação de campanhas e desafios para os calouros. Para que dessa forma consigam entender o funcionamento da universidade, e ajudá-los a se agrupar e interagir com outros cursos e estudantes.

Usando essa estratégia, além do que propõe as Novas Diretrizes Curriculares dos Cursos de Graduação em Engenharia, Resolução no 2 de 29 de abril de 2019 que deve estabelecer programa de acolhimento para os calouros, faz com que aproveitem melhor as oportunidades que o curso e a Universidade pode prover, tanto para sua vida profissional, tanto para o desenvolvimento psicológico.

Visto que, normalmente, a maior parte dos calouros vêm direto do Ensino Médio Regular, onde tem seus grupos de amizades e onde passam a maior parte do dia. E que, quando mudam para outro ambiente é bem comum se sentirem deslocados, principalmente nos primeiros semestres do curso. Por isso com a ajuda e incentivo da Universidade muitos conseguem crescer e desenvolver um pensamento mais maduro diante dos desafios, conseguem superar alguns de seus medos. Com tudo isso é possível observar a importância das atividades de acolhimento que muitas Universidades estão aderindo atualmente.

\section{IDENTIFICAÇÃO DE LACUNAS}

A UFRGS integra milhares de alunos, professores, pesquisadores e funcionários, inevitavelmente tem problemas e falhas estruturais nas áreas de serviços, processos e produtos. Com a visão e pensamento fora da caixa por parte dos alunos que não conhecem a UFRGS é possível a identificação das lacunas que passariam despercebidas para outras pessoas que convivem com o problema e se acostumaram. Tendo isso em mente, a escola de engenharia desenvolveu um projeto a fim de preencher essa necessidade dos alunos de integração e adaptação em um ano tão crítico com a da universidade de se modernizar e se tornar cada vez mais sustentável. É proposto aos alunos que por meio de suas experiências e o uso de metodologias de análise de falhas, criem projetos que tenha um viés que se alinhe aos objetivos de desenvolvimento sustentável da ONU.

Algumas dessas metodologias já são conhecidas e vastamente utilizadas na Engenharia, como Cinco Porquês e Diagrama de Ishikawa (também conhecido como "Espinha de Peixe") (ENGETELES, 2019). Essas ferramentas ajudam a aprimorar uma das competências essenciais de um engenheiro, a identificação de lacunas. Sendo assim, os alunos da Universidade são introduzidos à rotina universitária: pesquisa; análise de dados; comunicação com diversas pessoas e entidades; e consequentemente, integração e união entre os calouros e a instituição de ensino.

\section{HABILIDADES E COMPETÊNCIAS DE UM ENGENHEIRO}

Antigamente bastava para os futuros engenheiros a capacidade de apresentarem bom domínio das teorias fundamentais, dos métodos e ferramentas mais usadas nas engenharias, porém nos dias de hoje isso não é suficiente para o exercício da profissão (SIMON et al, 
2002). Por isso, o ensino de engenharia tem focado menos nos conhecimentos formais e mais nas competências e habilidades do engenheiro, sem deixar de lado a parte técnica.

O engenheiro moderno precisa ser capaz de resolver problemas, de encontrar soluções inovadoras e criativas que contribuam positivamente com o aspecto social e ambiental. Além de ter habilidade em pesquisa para projetar e conduzir experimentos. Habilidade para usar as tecnologias atuais e desenvolver novas, ou seja, nunca parar de se atualizar. Relacionado a isso ter a flexibilidade para se adaptar às mudanças e entender o mercado, muitos empreendedores são formados em engenharia.

Engenheiros também precisam ser bons líderes, por isso, a tomada de decisão é uma competência muito importante quando aliada ao bom trabalho em equipe e a habilidade de se expressar claramente.

Basicamente o engenheiro da atualidade precisa ser muito bem atualizado, estar por dentro de tudo que acontece no mundo, e ser capaz de aplicar tudo isso no seu projeto, pois essa é uma profissão cada vez mais interdisciplinar, visto que apenas o conhecimento técnico não é suficiente, é preciso habilidades e competências das mais variadas para formar o profissional engenheiro.

\section{INOVAÇÃO E EMPREENDEDORISMO}

Empreendedorismo é a capacidade de uma pessoa localizar oportunidades e problemas, e através disso, encontrar soluções ou novas formas de realizar uma atividade de forma que a sociedade seja impactada positivamente. Empreendedor é quem tem essa capacidade e a coloca em prática, além de ter virtudes essenciais como liderança, iniciativa, criatividade, coragem para se arriscar e persistência, isto é, não desistir se alguma ideia não funcionar. Inovação pode ser a criação de algo novo para o mercado ou a solução de algum problema já existente, tanto em relação a produtos quanto a serviços. Empreender e inovar estão atrelados e só funcionam harmonicamente se o empreendedor realmente colocar em prática suas ideias, saindo do comodismo, e assim, inovar. Empresas que não buscam inovação acabam perdendo espaço e não continuam crescendo no mercado. (SEBRAE, 2019; SEBRAE, 2020)

A inovação é fundamental para o crescimento econômico mundial e é movida pelo empreendedorismo. Visualizar oportunidades e explorar novas ideias pode ser o diferencial para um novo empreendedor ter sucesso e superar os mais experientes do âmbito, gerando uma competitividade positiva entre as empresas pela busca de produtos e serviços inovadores. O empreendedorismo está presente tanto nas startups, com a busca de criar algo novo e promissor, quanto nas empresas já estabelecidas que precisam renovar o que oferecem ao mercado consumidor. A busca por novas alternativas nem sempre é focada apenas nos lucros, há também o chamado empreendedorismo social, que visa mudanças ou melhora de condições na esfera social ou ambiental.

O ponto principal para um empreendimento deve ser saber gerenciar a inovação. Enquanto muitas empresas não possuem grande longevidade, há aquelas que conseguem se manter em funcionamento por mais de um século, como a empresa automotiva Rolls-Royce, que desenvolveu maneiras de gerenciar o processo, inovando ao longo dos anos seu 
produtos. Por isso, o empreendedor deve continuamente buscar oportunidades para tornar seu serviço ou produto atrativo ao mercado. (BESSANT; TIDD, 2009)

\section{SUSTENTABILIDADE E RESPONSABILIDADE SOCIAL}

Ações são caracterizadas como sustentáveis quando visam suprir as necessidades atuais dos seres humanos sem comprometer o futuro da sociedade, ou seja, ela está diretamente relacionada ao desenvolvimento econômico e material quando não há agressão ao meio ambiente, usando os recursos naturais de forma inteligente para que eles não esgotam posteriormente. Concomitantemente, segundo Pereira (2017) a responsabilidade social é a responsabilidade que uma instituição toma em prol da sociedade, com o objetivo de melhorar a qualidade de vida da sociedade e cuidar do meio ambiente.

Partindo-se do pressuposto que tecnologias do futuro irão impulsionar negócios mais sustentáveis, abrindo um leque de opções para as empresas agregarem valor, torna-se essencial descobrir novas formas para empresas, que atuam em ambientes cada vez mais complexos, incorporarem a visão de sustentabilidade econômica, social e ambiental em suas estratégias de negócios. Isto porque as tecnologias que impulsionam negócios bem sucedidos e sustentáveis serão aquelas que, desde a formulação estratégica até as etapas finais do processo de pesquisa e desenvolvimento $(\mathrm{P} \& \mathrm{D})$ e de inovação tecnológica incorpora os valores éticos da sustentabilidade (CORRÊA, 2010).

\section{RELIQUA BIOGÁS}

Reliqua Biogás é proposto por calouros da Escola de Engenharia da Universidade Federal do Rio Grande do Sul no projeto Acolhimento dos Calouros da EE - Desafio "Como tornar a UFRGS mais sustentável”. É composto por seis integrantes, dos cursos de Engenharia Física, Engenharia de Materiais, Engenharia Mecânica e Engenharia Química.

O projeto em questão estuda a viabilidade da implementação de um biodigestor para geração de biogás no Hospital de Clínicas de Porto Alegre e é alicerçado nos 17 Objetivos do Desenvolvimento Sustentável - ODS da Organização das Nações Unidas, entre eles, o objetivo 7 de assegurar o acesso confiável, sustentável, moderno e a preço acessível à energia para todos, o objetivo 11 de tornar as cidades e os assentamentos humanos sustentáveis e o objetivo 13 de tomar medidas para combater a mudança climática e seus impactos (ONU, 2015).

Neste sentido, o projeto justifica-se pela necessidade de redução de custos quanto a geração de resíduos sólidos orgânicos do Hospital de Clínicas de Porto Alegre (HCPA), pela geração de biofertilizante, biogás para geração de energia térmica, em substituição ao GLP, gasodutos GN e/ou energia veicular como GNV há uma considerada redução no potencial de poluição do meio ambiente, uma vez que é composto por uma alta concentração de gás metano $\left(\mathrm{CH}_{4}\right)$, cerca de 24 vezes superior ao dióxido de carbono $\left(\mathrm{CO}_{2}\right)$, no que se refere gases de efeito estufa (GEE). 
Para alcançar tal objetivo, utilizou-se da metodologia Design Thinking que caracterizase como uma abordagem, uma forma de pensar, e encarar problemas, focada na empatia, colaboração e experimentação, além disso o grupo envolvido na realização do projeto se concentrou na capacitação da equipe através de cursos e estudos disponibilizados e desenvolvidos a partir de uma parceria entre a Unido e o CIBiogás por meio do Projeto GEF Biogás Brasil que prevê ações locais e federais de estímulo à integração do biogás na cadeia produtiva brasileira, além de contar com o apoio para informações da equipe da unidade de demonstração de biogás e biometano instalada na Itaipu Binacional.

O projeto promoveu a integração e o desenvolvimento das habilidades cognitivas dos membros da equipe, como a criatividade, criticidade, indução, empreendedorismo, análise de riscos e ser capaz de resolver problemas, assim como possibilitou a discussão sobre a descentralização da tecnologia envolvida na geração de biogás nas regiões de produção agrícola e sobre a inovação na forma de destinação dos resíduos sólidos orgânicos urbanos gerados nas pequenas e grandes cidades.

\section{RESULTADOS ESPERADOS}

Devido a qualidade dos projetos, alguns receberam certificado destaque junto a Escola de Engenharia dando segmento no projeto como por exemplo Bolsa de Empreendedorismo (BIE) ofertado pela Secretaria de Desenvolvimento Tecnológico (SEDETEC) da UFRGS e ainda outros estão buscando auxilio junto ao Fundo Centenário da EE que tem como objetivo auxiliar as universidades de diversas maneiras, também conhecido como Endowment funds ou fundos patrimoniais ou filantrópicos que são recursos advindos de doações de pessoas físicas e/ou pessoas jurídicas.

Ainda, tem-se a possibilidade de bolsas junto as agências de fomento como Conselho Nacional de Desenvolvimento Científico e Tecnológico - CNPq e Fundação de Amparo à Pesquisa no Estado do Rio Grande do Sul - FAPERGS e também parcerias externas.

Através dessa inciativa de possibilitar ao acadêmico de ser inserido em pesquisas, apresentação de PITCH, elaborar artigos, participação de editais é uma forma de fazer com que aumente o interesse na Engenharia e ainda em empreender, inovar, ser ousado e estar atento as mudanças tecnológicas e das novas exigências que elas acarretam, fortalecer o intercâmbio de conhecimento entre alunos veteranos e calouros, pois, os veteranos, mestrandos e doutorandos são os mentores dos projetos.

O projeto intitulado Reliqua Biogás foi destaque no projeto Acolhimento dos Calouros da Escola de Engenharia - Desafio "Como tornar a UFRGS mais sustentável" da Universidade Federal do Rio Grande do Sul, tendo recebido bolsa de empreendedorismo, além de publicar a ideação do projeto em Congressos voltados para gestão de resíduos.

Ainda, espera-se do projeto Reliqua Biogás a inovação quanto a gestão de resíduos sólidos orgânicos a partir da produção de biogás para energia térmica e GNV, e biofertilizante que se constitui como uma alternativa melhor aos fertilizantes químicos que normalmente são explorados em áreas de mineração distantes das áreas de agricultura, causando impactos ambientais no local e durante a produção e transporte, além de promover a descentralização desse tipo de tecnologia em regiões de produção agrícola e discussões sobre como garantir um futuro econômico, social e ambientalmente sustentável.

Alguns objetivos específicos que ainda pretende-se alcançar são a análise do potencial de produção de metano dos substratos, dimensionamento da planta de biogás, criação de 
"Os desafios para formar hoje o engenheiro do amanhã"

um projeto de negócios a partir da análise de viabilidade inicial e parcerias para fabricação de

modelo piloto. Com isso, será possível confirmar a efetividade do projeto Acolhimento dos Calouros em inserir seus alunos no mundo da inovação e do empreendedorismo, característica tão essencial para a formação de um Engenheiro.

\section{REFERÊNCIAS}

BESSANT, John; TIDD, Joe. 2009. Inovação e Empreendedorismo.Disponível em: https://books.google.com.br/books?hl=pt-

$\mathrm{BR} \& \mathrm{lr}=\& \mathrm{id}=\mathrm{mV} 6 \mathrm{kDwAAQBAJ} \& \mathrm{oi}=\mathrm{fnd} \& \mathrm{pg}=\mathrm{PR} 1$

$\& \mathrm{dq}=$ inova\%C3\%A7\%C3\%A3o+e+empreendedorismo\&ots=N19vhuTNbD\&sig=ayw5RI A2JU2sPdvW65iGdDd7cc\#v=onepage \&q=inova\%C3\%A7\%C3\%A3o\%20e\%20empreend edori smo\&f=false. Acesso em: 27 maio. 2020

CONFEDERAÇÃO NACIONAL DA INDÚSTRIA.Fortalecimento das Engenharias. 2015. Confederação Nacional da Indústria. Disponível em: <http://arquivos.portaldaindustria.com.br/app/conteudo_24/2015/08/31/550/fortalecimento das engenharias_web2.pdf>. Acessado em: 28 maio. 2020.

CORDEIRO, J. S. et al. Um futuro para a educação em engenharia no brasil: desafios e oportunidades. Revista de Ensino de Engenharia, v. 27, n. 3, p. 69-82, 2008.

CORRÊA, D. A.; NETO, M. S.; SPERS, V. R. E.; GIULIANI, A. C. Inovação, sustentabilidade e responsabilidade social: análise da experiência de uma empresa de equipamentos pesados. Dalila Alves Corrêa, Mário Sacomano Neto, Valéria Rueda Elias Spers, Antonio Carlos Giuliani Revista de Gestão Social e Ambiental 4 (3), 90-105, 2010.

ENGETELES, 2019. 4 Ferramentas para Análise de Falhas.Disponível em: https://engeteles.com.br/ferramentas-para-analise-de-falhas/. Acesso em: 30 de maio. 2020.

LOUREIRO, S. M.; PEREIRA, V. L. D. V.; JÚNIOR, W. P. A sustentabilidade e o desenvolvimento sustentável na educação em engenharia. Revista Eletrônica em Gestão, Educação e Tecnologia Ambiental. Santa Maria, v.20, n.1, p. 306-324, 2016.

MARCO ANTÔNIO P. T.; ANA CRISTINA G. D.; SHANA H. W.; ADRIANO M. O. Adaptação à universidade em jovens calouros. Revista Semestral da Associação Brasileira de Psicologia Escolar e Educacional (ABRAPEE), São Paulo, Volume 12, 2008, Número 1, 185-202, Janeiro/Junho 2008.

ORGANIZAÇÃO DAS NAÇÕES UNIDAS. 17 objetivos de desenvolvimento sustentávelDisponível em: https://nacoesunidas.org/conheca-os-novos-17-objetivos-dedesenvolvimento-sustentavel-da-onu/. Acesso em: 20 maio. 2020.

PEREIRA. A. C.; SILVA G. Z.; CARBONARI M. E. E. Sustentabilidade, Responsabilidade Social e Meio Ambiente. Saraiva Educação S.A, 6 de outubro de 2017.

SERVIÇO BRASILEIRO DE APOIO ÀS MICRO E PEQUENAS EMPRESAS, 2020. Empreendedorismo e inovação: a moeda para o sucesso nos negócios.Disponível em: https://blog.sebrae-sc.com.br/empreendedorismo-e-inovacao/. Acesso em: 27 maio. 2020. 
SIMON, F, O.; BARROS FILHO, J.; SILVA, D.; SÀNCHEZ, C. G., 2002. Algumas tendências sobre habilidades e competências exigidas nos cursos de graduação em engenharia. In: CONGRESSO BRASILEIRO DE ENSINO DE ENGENHARIA, 30., 2002, Piracicaba. Anais eletrônico. Piracicaba: ABENGE, 2002, [CD-ROM].

SIMON, Fernanda Oliveira de. Habilidades e Competências em Engenharia: Criação e Validação de um Instrumento. 2004. Disponível em: http://repositorio.unicamp.br/bitstream/REPOSIP/253591/1/Simon_FernandaOliveira_M.p df Acesso em: 28 de maio de 2020.

\title{
INNOVATE AND ENTREPRENEUR IN THE FEDERAL UNIVERSITY OF RIO GRANDE DO SUL ENGINEERING SCHOOL: NEWS CHALLENGE 2020/1
}

\begin{abstract}
The challenge of training entrepreneurial and innovative engineers at the School of Engineering (EE) of the Federal University of Rio Grande do Sul (UFRGS) arises from the moment when the freshmen of the 13 engineering courses are inserted in the University and being challenged to propose projects of improvements that have a sustainable bias, covering the economic, social and environmental spheres and still align with the 17 UN Sustainable Development Goals. Also, they are presented to the various academic environments of the University, such as Junior Companies, Technological Development Secretariat (SEDETEC), Centenary Foundation, Laboratories and from there take advantage of the University's infrastructure to create, innovate and undertake and develop projects, interact with other areas knowledge, search for alternatives to the problems presented, aiming at intervention, continuous improvement and, proposing sustainability solutions, where the object is to use existing resources or improve them. Thus, the Reliqua Biogás project proposed by EE freshmen appears in the EE Freshmen Reception project Challenge "How to make UFRGS more sustainable". The project in question studies the feasibility of implementing a biodigester for biogas generation at Hospital de Clinicas de Porto Alegre, justified by the large volume of organic solid waste generated by the Institution and the need for innovation in the management of this waste as well as reducing costs with their destination.
\end{abstract}

Keywords:Engineering. Sustainability. Biogas. Innovation. Challenge. 